\title{
Wie sich die Person ausdrückt
}

Jürg Kesselring

Korrespondenz:

Prof. Dr. med. Jürg Kesselring Chefarzt Neurologie

Rehabilitationszentrum CH-7317 Valens

Tel. 0813031408

Fax 0813031410

kesselring.klival@spin.ch
Ich schreibe gerne im alten Stil mit Füllfederhalter auf Papier. Ein kleines Auf und $\mathrm{Ab}$ und Hin und Her der Fingerspitzen gliedert die Tintenlinie so, dass sie etwas von mir aussagt. Striche, Bögen, Längen, Lücken, Pausen. Woher der Bewegungsimpuls kommt, weiss ich nicht so genau. Alter Sprachgebrauch sagt: Ich denke, er kommt von mir. Als Neurologe bin ich gewohnt, mir vorzustellen, dass ein Impuls zur Tat sich im Gehirn bildet, je nachdem, was ich schreiben will, und dies wiederum wird geprägt von den Zielen, die ich verfolge, von den inneren und äusseren Möglichkeiten, die mir gegeben sind, von den Erinnerungen, die einfliessen.

Und wenn ich die kleine Fingerschrift von der Folie auf eine Leinwand projiziere, ist sie so gross, dass ich ganz andere Muskeln brauche, um sie nachzuzeichnen: Schultern, Biceps, Triceps, ganz andere Kräfte. Und doch bleibt das Schriftbild das gleiche, unverwechselbar, ein Ausdruck von mir selbst. Andere Muskeln kann ich ebenso benutzen: Ich schreibe mit dem Fuss in den Sand «Ich liebe Dich...», bevor die Fluten die äusseren Spuren meiner Freude überspülen.

Eine Patientin war nach der Kinderlähmung 30 Jahre lang fast vollständig gelähmt, konnte nicht einmal selbst atmen, nur den Kopf bewegen, und als sie nach all den Jahren mit dem Mund zu malen und zu schreiben lernte, den Pinsel oder Griffel fest zwischen die Zähne geklemmt und nur von der scheinbar plumpen Nackenmuskulatur geführt, näherte sich ihre neu gelernte Schrift immer mehr ihrer früheren Handschrift an, die sie vor Jahren nach aussen hin verloren, aber doch in ihrem Inneren bewahrt hatte - in ihrem Herzen? Ein Bauer wurde wegen seiner «Handschrift» überführt, als er dem Nachbarn mit Rattengift vors Tor geschrieben hatte: «Du Mistkerl» - da war die ganze Person am Schreiben gewesen, hin und her sausend über den Hof, Gift versprühend. Rekruten sollen beim Austreten im Schnee anhand der gelblichen Spuren überführbar gewesen sein, mit denen sie an stillem Örtchen ihre Vorgesetzten verunglimpfen wollten. Unverkennbar, unverlierbar ist die Persönlichkeit, die ihren Ausdruck sucht und in der Bewegung findet. Ohne Bewegung bleibt bestenfalls ein Gedankenstrich. Ob wir genug von unserer Persönlichkeit in E-Mail und SMS transportieren können, ob also damit, wie der Ausdruck Per-son meint, genug von uns nach aussen dringt und klingt?

Lichtenberg war der Ansicht, dass das Blei mehr als das Gold die Welt verändert habe und mehr als das Blei in der Flinte das Blei im Setzkasten. Aber verändert wurde die Welt allerdings nicht durch das Blei, solange es im Setzkasten war, sondern erst, als es von kundigen Händen aus diesem geholt wurde, nachdem ebenso kundige Hände das Blei aus einer althergebrachten, heissen, flüssigen Mischung mit Antimon und Zinn nach weithergeholten Vorlagen und Schablonen zu Buchstaben als bewegliche Lettern gegossen und diese in die richtige Reihenfolge gesetzt hatten. Und «kundig» meint ja, dass jemand etwas weiss und kann. Die Buchstaben des Alphabetes sind ein Code, ähnlich dem genetischen - wenige Einheiten eröffnen durch Kombinationen unendliche Möglichkeiten der Verschiedenartigkeit. Manchmal wird behauptet, Ähnlichkeit im Code bedeute Ähnlichkeit des Wesens, z. B. dass der genetische Code von Schimpansen und Menschen $\mathrm{zu}>95 \%$ identisch sei und deshalb ... Wenn man sorgfältig die Bücherwände durchforstet, wird man sogar eine noch viel höhere Übereinstimmung des Grundmusters finden - alle (= $100 \%)$ unsere Bücher sind mit den 25 Buchstaben des Alphabetes geschrieben. Aber deren Anordnung, die von einem Willen gesteuert ist, macht aus, dass Schriften, wie Sprachen, wie wir selbst, ganz verschieden sind und ganz unterschiedliche, individuelle Inhalte transportieren können. Mit diesen wollen wir der Welt antworten und sie verantworten, auch wenn es Fragen sind.

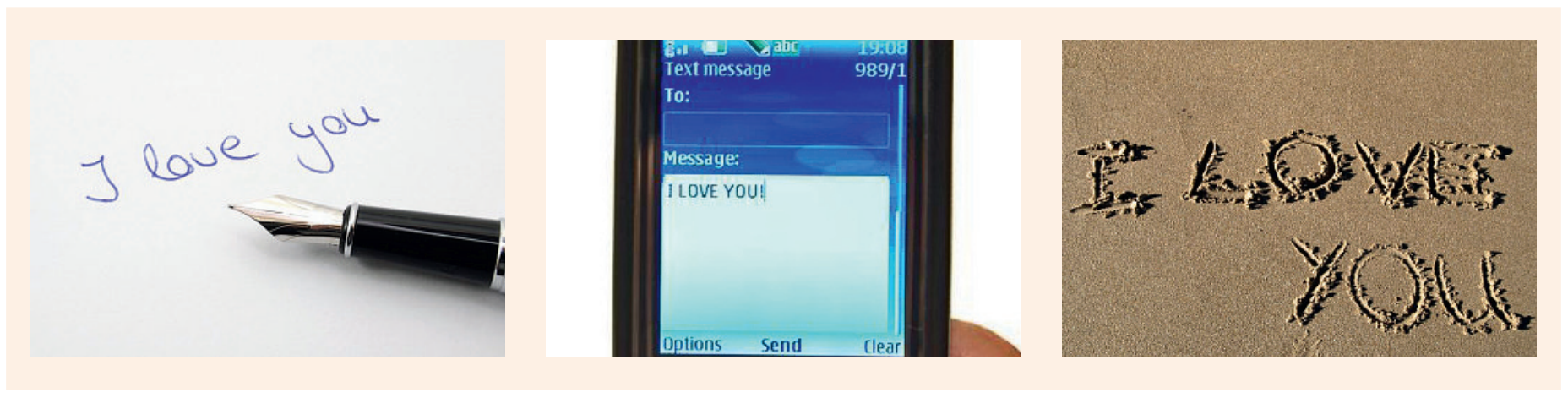

